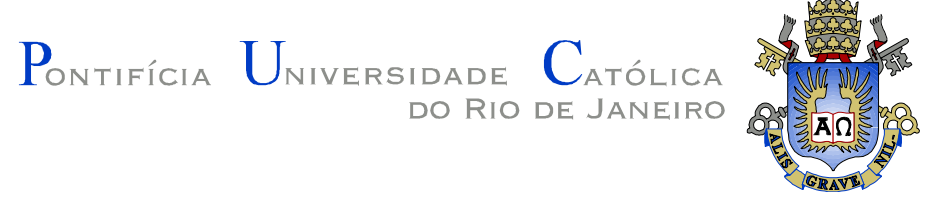

María Paulina Romero Obando

\title{
ESTUDO DA INTERAÇÃO DE FOTOSSENSIBILIZANTES DERIVADOS DE FTALOCIANINAS COM SISTEMAS DE DISTRIBUIÇÃO DE FÁRMACOS PARA TERAPIA FOTODINÂMICA
}

Tese de Doutorado

Tese apresentada como requisito parcial para obtenção do título de Doutor em Física pelo Programa de Pós-Graduação em Física do Departamento de Física da PUC-Rio.

Orientadora: Sônia Renaux Wanderley Louro

Rio de Janeiro

Abril de 2012 


\section{ESTUDO DA INTERAÇÃO DE FOTOSSENSIBILIZANTES DERIVADOS DE FTALOCIANINAS COM SISTEMAS DE DISTRIBUIÇÃO DE FÁRMACOS PARA TERAPIA FOTODINÂMICA}

Tese apresentada como requisito parcial para obtenção do grau de Doutor pelo Programa de Pós-Graduação em Física do Departamento de Física do Centro Técnico Científico da PUC-Rio. Aprovada pela Comissão Examinadora abaixo assinada.

Profa. Sônia Renaux Wanderley Louro Orientadora Departamento de Física - PUC-Rio

Profa. Aurora Pérez-Gramatges UFRJ

Profa. Eliane Wajnberg CBPF

Prof. Marco Cremona Departamento de Física - PUC-Rio

Prof. Osvaldo Antonio Serra FFCLRP - USP

Prof. José Eugênio Leal Coordenador Setorial de Pós-Graduação Centro Técnico Científico - PUC-Rio

Rio de Janeiro, 20 de abril de 2012 
Todos os direitos reservados. É proibida a reprodução total ou parcial do trabalho sem autorização da universidade, do autor e da orientadora.

\section{María Paulina Romero Obando}

Graduou-se em Física na EPN (Escuela Politécnica Nacional- Equador) em 2007.

Ficha Catalográfica

Romero Obando, María Paulina
Estudo da interação de fotossensilizantes
derivados de ftalocianinas com sistemas de
distribuição de fármacos para terapia fotodinâmica /
María Paulina Romero Obando ; orientador: Sônia
Renaux Wanderley Louro. - 2012 .
149 f. : il.(color.) ; 30 cm
Tese (doutorado)-Pontifícia Universidade
Católica do Rio de Janeiro, Departamento de Física,
2012.
Inclui bibliografia

CDD: 530 
Só temos consciência do belo

Quando conhecemos ofeio, Só temos conciência do bom Quando conhecemos o mau. Porquanto o Ser e o Existir Se engendram mutuamente. O fácil e o difícil se completam. O grande e o pequeno são complementares.

$O$ alto e o baixo formam um todo. O som e o silêncio formam a harmonia. O passado e o futuro geram o tempo. Eis por que o sábio age Pelo não-agir. E ensina sem falar. Aceita tudo que lhe acontece. Produz tudo e não fica com nada. O sábio tudo realiza - e nada considera seu. Tudo faz-e não se apega à sua obra. Não se prende aos frutos da sua atividade. Termina sua obra E está sempre no princípio. E por isto a sua obra prospera.

Poema 2. Tao Te Ching. Lao-Tsé 
Dedico a:

Minha filha Cristina Cecibel, que tem sido a fonte de minha inspiração, de meu amor e minha felicidade.

A minha família Angel, Yolanda, Silvana, Milton, Monica, por estar sempre comigo, incondicionalmente, me apoiando e acreditando sempre em mim. 


\section{Agradecimentos}

Como sempre, a Deus, pelas graças recebidas e por estar sempre comigo me guiando.

A minha orientadora a Professora Sonia Louro, por sua dedicação, ensinamentos e paciência infinita.

A meus grandes amigos Mary y Fernando, sem cuja amizade incondicional a vida teria sido complicada. Levarei no meu coração os grandes momentos vividos.

A meus amigos e colegas da Física da PUC-Rio, pelo ótimo convívio e grande amizade. Ao pessoal do antigo "sexto andar" Kelly, Vanessa, Thiago, Fabio, Johanna, Alexandre, Jefferson pela amistad, carinho e ajuda enorme recebida.

A todos os professores da Física pelos conhecimentos recebidos e pela acolhida, aos moradores da Estrada da Gávea 6, pelo ótimo convívio, simpatia e amistad.

A Giza, secretária da Física PUC-Rio, Graça, secretária do CLAF pela enorme ajuda e amplo sorriso recebido em todo este tempo.

Ao CLAF, CNPq, INAMI pelo apoio financeiro.

Ao povo Brasileiro, pela qualidade de pessoas, sua amabilidade e carinho com que receberam a mim, minha filha e minha família. Obrigada! 


\section{Resumo}

Romero Obando, María Paulina. Estudo da interação de fotossensibilizantes derivados de ftalocianinas com sistemas de distribuição de fármacos para terapia fotodinâmica. Rio de Janeiro, 2012. 149p. Tese de Doutorado - Departamento de Física, Pontifícia Universidade Católica do Rio de Janeiro.

A Terapia Fotodinâmica (PDT) consiste na irradiação com luz visível de um tecido após a aplicação de um fotossensibilizante. São produzidas diferentes espécies reativas, em especial oxigênio singleto, que desencadeiam uma série de eventos que resultam na inativação ou morte celular. $O$ desenvolvimento de fotossensibilizantes e o estudo de sua distribuição aos locais das lesões são importantes para ampliar as aplicações de PDT. O objetivo deste trabalho foi avaliar as propriedades de ftalocianinas associadas a surfactantes que facilitassem a distribuição e atividade fotocatalítica desse tipo de fotossensibilizante. Foram utilizadas as propriedades espectroscópicas de absorção e fluorescência dos fotossensibilizantes. Numa primeira etapa, foi avaliada a ftalocianina de zinco ( $\mathrm{ZnPc}$ ) em formulações com diferentes surfactantes iônicos (SDS, CTAB, HPS) e não iônicos (Tween 20, Tween 80, Pluronic F-68, PF-127, Triton X-100). Encontrou-se que soluções concentradas de ZnPc e surfactante em DMF ou DMSO formam nanoemulsões instáveis em solução aquosa. No início, ZnPc apresenta-se monomérica nessas nanoemulsões, mas sofre agregação com o passar do tempo, diminuindo sua eficiência como sensibilizante. A cinética de agregação mostrou que HPS e CTAB formam as nanoemulsões mais estáveis, com tempos característicos de formação de agregados superiores a dois dias. Em seguida foi avaliado um novo derivado mentolado de ftalocianina, MentaZnPc, sintetizado por K. Oliveira e colaboradores, em micelas dos surfactantes acima, além dos polioxietilenos C12E9 e Brij 30, 35, 97 e 98. A presença dos grupos mentol como substituintes diminuiu a tendência de empilhamento e produziu maior solubilidade no compartimento hidrofóbico das micelas. Foram avaliados rendimentos quânticos de fluorescência, de produção de oxigênio singleto, usando DPBF como sonda, e fotobranqueamento dos fotossensibilizantes nos meios microheterogêneos. As melhores condições para a geração de ${ }^{1} \mathrm{O}_{2}$ por $\mathrm{ZnPc}$ foram encontradas em nanoemulsões de HPS. Por outro lado, MentaZnPc apresentou 
ótimo rendimento quântico de oxigênio singleto em micelas não iônicas, especialmente em PF-127, já utilizado amplamente na indústria farmacêutica.

\section{Palavras-chaves}

Biofísica, ftalocianina, surfactantes, fotossensibilizante, terapia fotodinâmica, espectrofotometria, fluorescência. 


\section{Abstract}

Romero Obando, María Paulina. Study of the interaction of phthalocyanine-derived photosensitizers with drug delivery systems for photodynamic therapy. Rio de Janeiro, 2012. 149p. Tese de Doutorado Departamento de Física, Pontifícia Universidade Católica do Rio de Janeiro.

Photodynamic Therapy (PDT) involves irradiation of a tissue with visible light after application of a photosensitizer. Different reactive species are produced, which initiate events that result in inactivation or cell death. The development of photosensitizers and the study of their delivery to sites of the lesions are important to broaden the applications of PDT. The objective of this study was to evaluate the properties of phthalocyanines associated with surfactants that facilitate the distribution and photocatalytic activity of this type of photosensitizer. The spectroscopic properties of absorption and fluorescence were used. In a first step, zinc phthalocyanine $(\mathrm{ZnPc})$ was evaluated in formulations with different ionic (SDS, CTAB, HPS) and nonionic surfactants (Tween 20, Tween 80, Pluronic F-127 and F-127, Triton X-100). It was found that concentrated solutions of the surfactants with $\mathrm{ZnPc}$ in DMF or DMSO form unstable nanoemulsions in aqueous solution. At first, $\mathrm{ZnPc}$ is monomeric in the nanoemulsions, but aggregates in the course of time, reducing its efficiency as a sensitizer. The kinetics of aggregation showed that HPS and CTAB form the more stable nanoemulsions with aggregation lifetimes greater than two days. Then, a new menthol phthalocyanine derivative, MentaZnPc, synthesized by K. Oliveira et al., was evaluated in micelles of the surfactants above, and of several polyoxyethylenes. The presence of menthol groups as substituents decreased the stacking tendency and produced a greater solubility in the hydrophobic compartment of the micelles. Fluorescence, singlet oxygen quantum yields and photobleaching of the photosensitizers were evaluated in the microheterogeneous media. The best conditions for ${ }^{1} \mathrm{O}_{2}$ generation by $\mathrm{ZnPc}$ were found in HPS nanoemulsions. MintZnPc presented an excellent singlet oxygen quantum yield in non-ionic micelles, especially in Pluronic F-127, which has been widely used in the pharmaceutical industry.

\section{Keywords}

Biophysics, phthalocyanines, surfactants, spectrophotometry, fluorescence, photosensitizer, photodynamic therapy. 


\section{Sumário}

1 Introdução 13

$\begin{array}{ll}1.1 \text { Objetivos } & 15\end{array}$

1.2 Estrutura dos capítulos 16

2 Princípios gerais 17

$\begin{array}{ll}2.1 \text { Processos fotofísicos em moléculas } & 17\end{array}$

2.2 Absorção óptica UV-Visível (eletrônica) 19

2.2.1 Lei de Beer- Lambert $\quad 20$

2.3 Processos de desexcitação 21

2.4 Interações intermoleculares e formação de agregados 24

2.5 Efeito da interação entre cromóforos na absorção 27

2.5.1 Formação de dímeros $\quad 27$

2.5.2 Hipocromismo $\quad 29$

2.6 Terapia Fotodinâmica 31

2.6.1 Mecanismo de ação 32

2.6.2 Oxigênio singleto $\quad 34$

$\begin{array}{lll}2.7 & \text { Fotossensibilizantes } & 37\end{array}$

$\begin{array}{ll}\text { 2.7.1 Histórico } & 37\end{array}$

$\begin{array}{ll}\text { 2.7.2 Ftalocianinas } & 39\end{array}$

2.8 Sistema de transporte de drogas 43

2.8.1 Classificação dos transportadores de droga 43

2.9 Interação de surfactantes com fotossensibilizantes 48

3 Técnicas Experimentais $\quad 51$

3.1 Instrumentação para medição da absorbância 51

3.1.1 Fatores que afetam as propriedades de absorção de um
cromóforo.

3.2 Instrumentação para Medição da Fluorescência 52

4 Materiais e Métodos $\quad 54$

4.1 Materiais $\quad 54$

4.2 Métodos 56

4.2.1 Preparação de ZnPc em nanoemulsões de surfactantes 56

4.2.2 Preparação de MentaZnPc em micelas 58

4.2.3 Processo de fotodegradação $\quad 58$

4.2.4 Taxas de fotoxidação $\quad 60$

4.2.5 Eficiência quântica $\quad 61$

$5 \quad$ ZnPc em micelas de diferentes surfactantes: absorção e fluorescência 67

5.1 ZnPc em DMSO, em DMF e adição de surfactantes 67

$5.2 \mathrm{ZnPc}$ em nanoemulsões de surfactante-DMSO ou -DMF 69 
5.3 ZnPc em diferentes concentrações de micelas de HPS E CTAB 82

5.4 Discussão e conclusões 83

6 Propriedades fotossensibilizantes de $\mathrm{ZnPc}$ em micelas 85

6.1 Atividade fotodinâmica avaliada por fotobranqueamento de $\mathrm{ZnPc} \quad 86$

6.2 Atividade fotodinâmica avaliada por fotoxidação de Trp 90

6.3 Atividade fotodinâmica avaliada com DPBF 95

6.4 Eficiência quântica de fluorescência $\Phi_{\mathrm{f}} \quad 100$

6.5 Eficiência quântica de oxigênio singleto $\Phi_{\Delta} \quad 102$

6.6 Conclusões 105

7 Estudos espectroscópicos de derivado mentolado de ftalocianina (MentaZnPc) em diferentes meios

7.1 MentaZnPc em dimetilformamida (DMF) e acetato de etila (EtAc) 110

7.2 MentaZnPc em diferentes soluções micelares 119

$\begin{array}{ll}7.3 \text { Atividade Fotodinâmica } & 124\end{array}$

7.4 Conclusões 134

8 Conclusão 137

$\begin{array}{ll}\text { Referências Bibliográficas } & 141\end{array}$ 


\section{Abreviações}

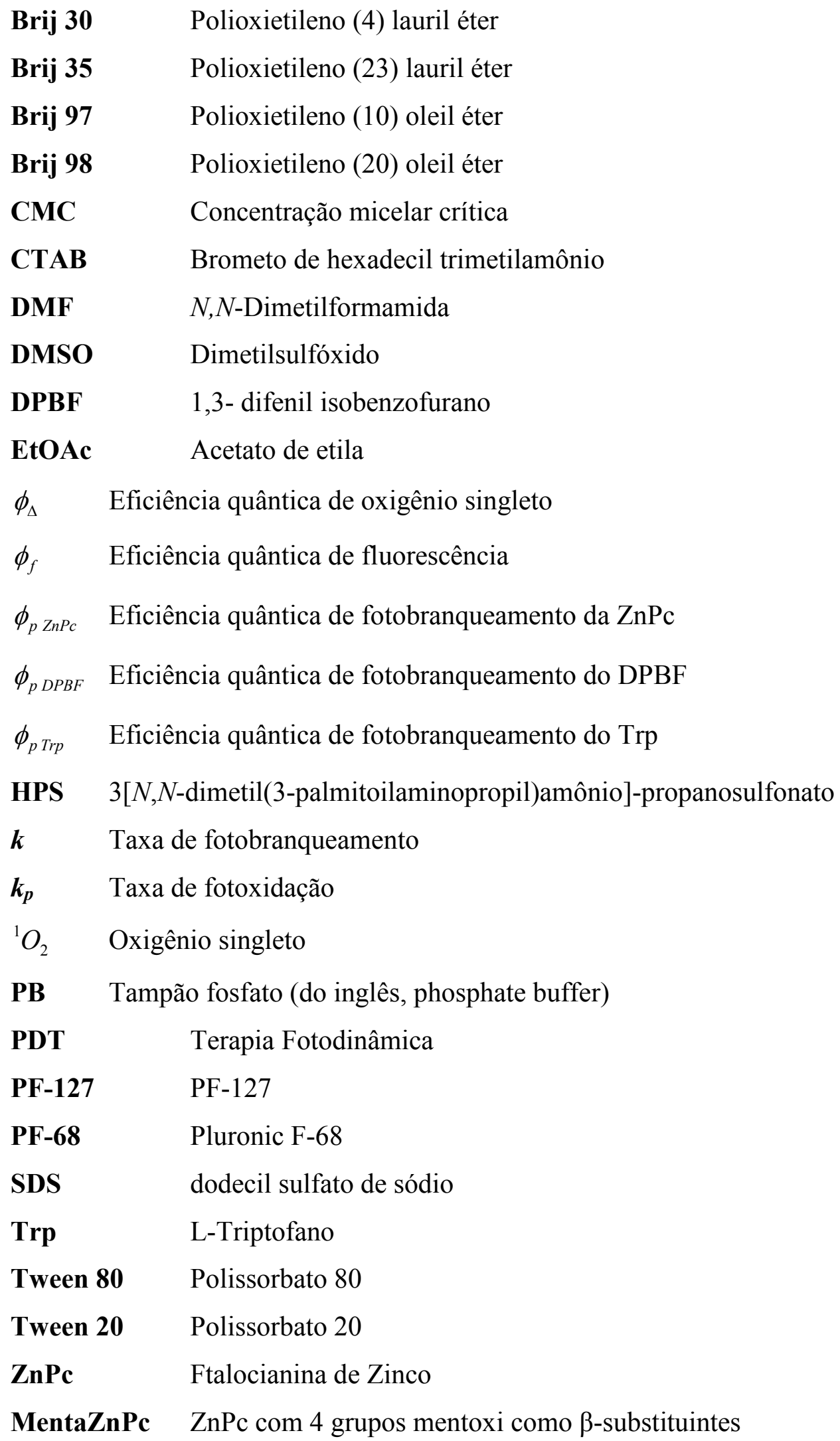

